\title{
Uses of vessel loops in plastic surgery
}

Sir,

Vessel loops are disposable, single-use medical device made of soft silicone rubber having multiple uses in different surgical specialties. These are available in multiple colours - red, blue, green, yellow, white and transparent. Apart from this, they are available in different size, thickness and cross-sections (round and oval) to be used for the size of the structures they are tagged with.

These loops are radiopaque and need to be sterilised (preferably gamma radiation) before use. The simplest method to secure it with the tagged structures is to hold it with the haemostat or else a ligaclip can be applied in place of haemostat to avoid excessive instrumentation in the operating field. 
We enumerate the uses of vessel loops in plastic surgery.

1. Identification of structures - artery, vein, nerve, tendon

2. End-to-side or side-to-side vascular anastomosis

3. Atraumatic retraction on perforator during its dissection

4. Delivery of nerve through a tunnel for coaptation

5. Small loops of vessel loops are used for retraction on nerve, vessels for endoscopic procedures

6. Closure of fasciotomy wounds

7. Finger Tourniquet.

Most common use of vessel loop is the identification of tagged structures as per colour of loops. The standard color for identification include: red for artery, blue for vein and yellow for nerve.

Vessel loop is very helpful for identification when multiple structures are available and having some common origin as in the infraclavicular dissection in brachial plexus. The branches from cords can be tagged with different coloured loops to avoid confusion.

Vessel loops are commonly used for end-to-side and side-to-side anastomosis of blood vessels. The vessel loops can be tightened adequately to stop the blood flow in the vessel so that bloodless field aids in perfect anastomosis. ${ }^{[1]}$

Vessel loops are very useful for atraumatic retraction of tagged structures. Even for fine vascular structures such as perforators during dissection for perforator-free flaps [Figure 1].

A small loop of a vessel loop can be used for retraction of nerve or vessels in endoscopic procedures.

It is used for delivery of nerve at the time of nerve transfer through the tunnel during direct coaptation of contralateral C7 through retropharyngeal route [Figures 2 and 3]. In this technique, a loop is passed through the tunnel (both the ends of vessel loop are in recipient area), the donor nerve is passed through the loop which is gently pulled to deliver the nerve to recipient area.

Vessel loops are used by many surgeons to slowly close the wounds, with the staples applied to the edges and vessel loops passed through these in the form of shoelace. The vessel loops are slowly tightened to

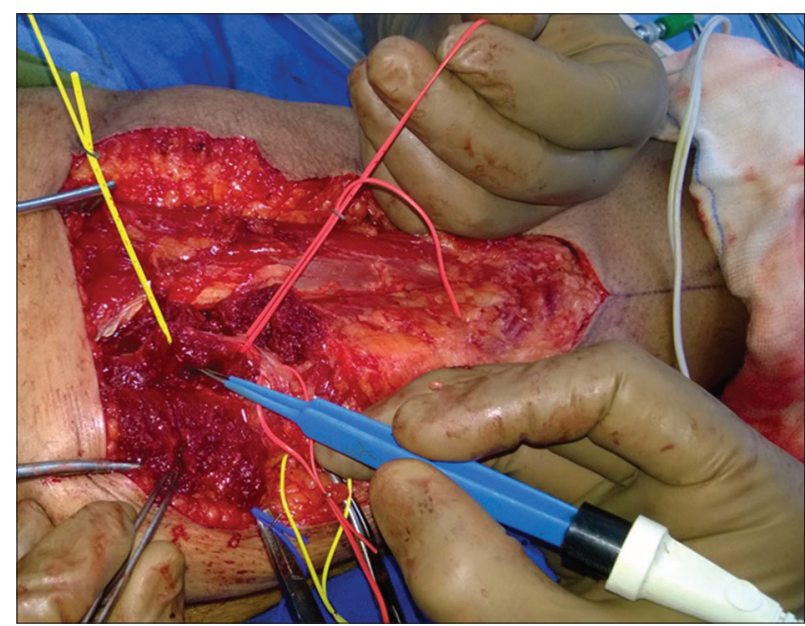

Figure 1: Atraumatic Retraction during perforator flap harvest

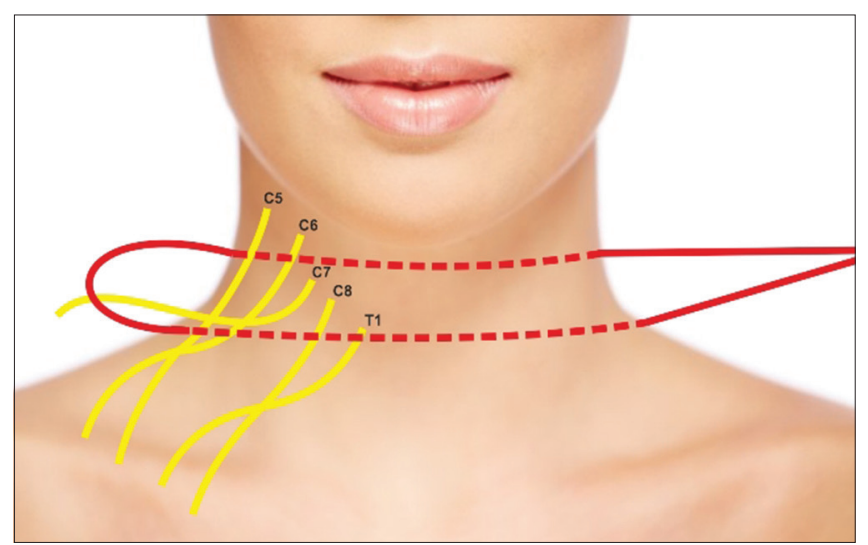

Figure 2: Vessel loop through retropharyngeal route for Contralateral C7 delivery

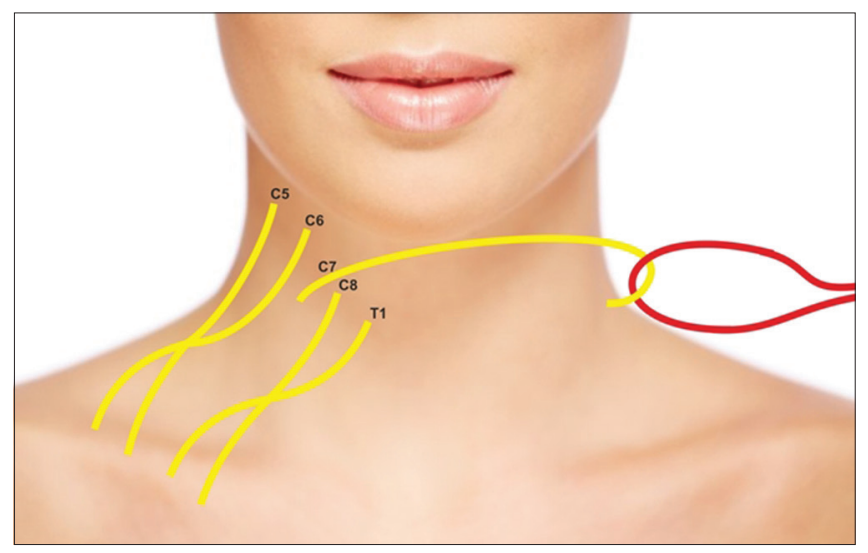

Figure 3: Atraumatic Delivery of nerve on pulling the vessel loop

get approximation of skin edges thus avoiding skin grafting. ${ }^{[2,3]}$

It can be used as a tourniquet during surgeries on finger and in hypospadias. The vessel loop can be used to exsanguinate the finger if the application starts from distal to proximal. After reaching the base of finger the 
distal part can be opened and tourniquet held in place with haemostat.

Apart from these uses in plastic surgery, vessel loops are used in other surgical specialties-gynaecology (ensuring the patency during LeFort colpocleisis), ${ }^{[4]}$ paediatric/general surgery (incision and drainage with vessel loops). ${ }^{[5]}$

\section{Financial support and sponsorship}

Nil.

\section{Conflicts of interest}

There are no conflicts of interest.

\section{Hardeep Singh, Rakesh Kumar Khazanchi, Aditya Aggarwal, Sanjay Mahendru, Vimalendu Brajesh, Sukhdeep Singh}

Division of Plastic, Reconstructive and Aesthetic Surgery, Medanta-The Medicity, Gurgaon,

Haryana, India

Address for correspondence:

Dr. Hardeep Singh,

Department of Plastic, Reconstructive and Aesthetic Surgery, Medanta-The Medicity, Sector 38, Gurgaon - 122 001, Haryana, India. E-mail: drhardeepaulakh@gmail.com

\section{REFERENCES}

1. Stahlfeld KR, Parker JE. Vessel loops made easy. J Vasc Surg 2001;34:172.
2. Baum TP, Strauch B. Delayed primary closure using silastic vessel loops and skin staples: Description of the technique and case reports. Ann Plast Surg 1999;42:337-40.

3. Schnirring-Judge MA, Anderson EC. Vessel loop closure technique in open fractures and other complex wounds in the foot and ankle. J Foot Ankle Surg 2009;48:692-9.

4. Dessie SG, Rosenblatt PL. Use of a vessel loop to ensure tunnel patency during leFort colpocleisis. Int Urogynecol J 2015;26:1541-3.

5. Tsoraides SS, Pearl RH, Stanfill AB, Wallace LJ, Vegunta RK. Incision and loop drainage: A minimally invasive technique for subcutaneous abscess management in children. J Pediatr Surg 2010;45:606-9.

This is an open access journal, and articles are distributed under the terms of the Creative Commons Attribution-NonCommercial-ShareAlike 4.0 License which allows others to remix, tweak, and build upon the work non-commercially, as long as appropriate credit is given and the new creations are licensed under the identical terms.

\begin{tabular}{|l|l|}
\hline \multicolumn{2}{|c|}{ Access this article online } \\
\hline Quick Response Code: & Website: \\
\hline
\end{tabular}

How to cite this article: Singh $\mathrm{H}$, Khazanchi RK, Aggarwal A, Mahendru S, Brajesh V, Singh S. Uses of vessel loops in plastic surgery. Indian J Plast Surg 2018;51:103-5.

(c) 2018 Indian Journal of Plastic Surgery | Published by Wolters Kluwer - Medknow 